\title{
Physical and Digital Innovation in Shipping: Seeding, Standardizing, and Sequencing
}

\author{
Richard T. Watson \\ University of Georgia \\ rwatson@terry.uga.edu
}

\author{
Mikael Lind \\ Viktoria Swedish ICT \& \\ University of Gothenburg \\ mikael.lind@viktoria.se
}

\author{
Sandra Haraldson \\ Viktoria Swedish ICT \\ sandra.haraldson@viktoria.se
}

\begin{abstract}
Two innovations within shipping are analyzed. (1) Containerization, an analog innovation that commenced about 50 years ago, created a new system for the handling of global trade and drove shipping costs to the point of financial irrelevance. (2) Sea traffic management is an EU digital innovation in process that aims to revolutionize the shipping business. We identify the seed innovation, which in each case initiates a standardization process and a series of sequenced and coordinated innovations that created a new transport system in one case, and are planned to fashion a smarter system in the second. We conclude with some research questions on seed innovations and the sequencing of innovations for new system emergence.
\end{abstract}

\section{A critical global problem}

The global shipping industry is responsible for around $90 \%$ of the world's trade [1] because it is the most cost-effective form of transport. A container ship can move the equivalent of several large warehouses of goods with a crew of about 13 . For instance, the cost of transporting a kilogram of coffee from Asia to Europe is only fifteen cents, or one percent of item cost. ${ }^{1}$ Because ships need to carry sufficient fuel for a voyage, they are powered by energy dense fossil fuels. With a yearly growth rate of about $4 \%$ [2], water borne transport will be a continuing source of carbon emissions for some years. Significantly, in 2007 ocean cargo shipping produced about 840 million metric tons of $\mathrm{CO}_{2}$ [3], approximately $2.7 \%$ of the estimated global carbon emissions. ${ }^{2}$ Without major changes in technology and policies, shipping could by 2050

\footnotetext{
$1 \quad \mathrm{http}$ //www.worldshipping.org/benefits-of-linershipping/efficiency

${ }^{2} \mathrm{http}$ ://co2now.org/Current-CO2/CO2-Now/global-carbonemissions.html
}

account for $17 \%$ of global $\mathrm{CO}_{2}$ emissions [4]. The industry is a sustainability slowcoach [5].

This article compares and contrasts two shipping innovations for improving efficiency and sustainability. Containerization, an analog innovation, was initiated 50 years ago, and sea traffic management, based on a digital innovation, is in the early stages of implementation.

\section{EU funded innovation}

In 2010, the European Union (EU) commenced a multi-year project to fund innovation in the shipping industry to improve efficiency, safety, and sustainability, goals which parallel the triple bottom line of profits, people, and planet [6]. The initial project, MONALISA 1.0, concentrated on increasing ship-to-ship collaboration through sharing routes among ships and shore-based vessel management authorities. The project operated in the Baltic Sea Region. This project was then extended, MONALISA 2.0 (2013-2015), to cover more regions in Europe with more partners and an increased budget. The focus, inspired by the Single European Sky Air Traffic Management Research (SESAR) project, was to enhance Sea Traffic Management (STM) by applying three concepts (voyage management, flow management, and port collaborative decision-making) supported by a digital data-sharing infrastructure. In 2015 , the project was renamed STM validation and the consortia was granted $€ 43$ million to validate STM concepts in 13 ports with over 300 participating ships. The EU sees acceleration of the industry's digitization as critical to meeting its goals, ${ }^{3}$ and it expects STM to revolutionize the shipping business.

The STM project's success will require the coordination and integration of multiple layers of innovation, from data messaging to governance.

\footnotetext{
${ }^{3}$ http://stmvalidation.eu
} 
Consequently, it can potentially learn from the previous widely changing innovation in the industry, containerization.

\section{An analog innovation in shipping}

Since 1956, when the first load of 58 containers was moved on a converted tanker from Newark, New Jersey to Houston, Texas, the cost of shipping by both sea and land has declined rapidly [7]. Because of the global adoption of containerization, "It is better to assume that moving goods is essentially costless than to assume that moving goods is an important component of the production process" [8]. While the shipping container was indubitably an innovation, the major innovation was the system that facilitated its global spread. The shipping of goods was transformed by a series of coordinated complementary innovations that drove freight costs to the point of irrelevance, such as illustrated by the prior coffee shipment example. There were many innovations gestated by the seed innovation of a container (Figure 1).

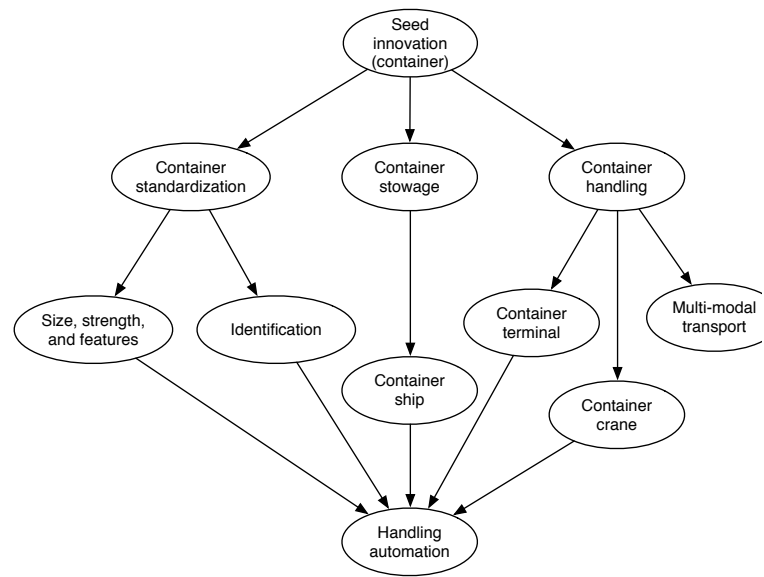

Figure 1: Containerization innovation

The notion of containerization appeared as early as the $18^{\text {th }}$ century [9], well before Malcom McLean took the idea and turned it into a low cost transport system by inventing the container ship and crane. The container was the seed idea that germinated other innovations that were necessary to make containerization efficient. McLean first tackled two key problems: how to stow containers on a ship and how to load and unload them at a dock.

Because of McLean's success, containers captured the attention of the transport industry in the late 1950s, but efficiency was blighted by the many different container sizes and both intra and intermodal incompatibilities. In 1958, the standardization process was initiated by the United States Maritime Administration, but because of the variety of interests affected by an international standard, it was not until the mid 1960s that the specification was completed in the form of ISO 668. Over the last half-century, the economic benefits of the containerization system have driven down shipping to a negligible component of the total cost for many items. Containers implement the principle of comparative advantage [10] globally.

The visible evidence of container-initiated innovation is seen in containers, ships, and cranes, but other innovations were also required, especially in the governance area, to ensure safety and interoperability across the globe.

As a UN agency, the International Maritime Organization (IMO) is concerned with the safe transportation of containers. It sets acceptable test procedures and related strength requirements for containers. The International Organization for Standardization (ISO) developed ISO 668 to specify the size and construction of containers to enable global interoperability and meet IMO requirements. It also gave to the Bureau International des Containers et du Transport Intermodal (BIC) the authority to uniquely identify and register each container.

Governance is a less visible side of innovation, but it was required to ensure industry wide adoption. New regulations needed to be created and old ones revised or rescinded. With standards in place, designers can innovate for efficiency within a physical component, such as a ship, and across components, such as ship to crane, to ensure efficient interoperability. Standardization laid the foundation for efficiency gains in multi-model transport and automation of container handling.

Currently, the world's largest container shipping company, Maersk, was a late-comer to the container business. Its success was determined not by a legacy of seafaring knowledge, but rather due to the new skills it developed in financial, managerial, and information systems [7] that were necessary to finance and operate a fleet of large container ships and manage the annual shipment of millions of containers. ${ }^{4}$ The container galvanized a stream of innovations in a variety of areas that radically changed global shipping in the space of a half-century.

As the EU pushes the shipping industry towards a digital future, there is a need to identify a parallel set of coordinated complementary innovations that are necessary to fulfill the EU's trifecta of efficiency, safety, and sustainability.

\section{Digital innovation in shipping}

\footnotetext{
${ }^{4}$ In 2106, Maersk operated 590 container ships and moved 4 million containers between Europe and Asia. http://www.maersk.com/en/the-maersk-group/facts-and-figures
} 
Digital data streams (DDS) are the seed innovation for digitizing shipping. A DSS is a continuous digital encoding and transmission of data describing the state of an entity, such as the location, direction, and speed of a ship, or a person, such as a politician's tweets. DDSs allow managers to dissect events in real-time, to shorten the decision cycle, and deepen understanding of customers at the same time. A DDS enables every asset to stream data about its current state and for the asset to be potentially controlled remotely [11].

The notion of a DDS did not arise in the shipping industry. It is an ICT innovation that has gained prominence as the notion of an Internet of Things (IoT) captures attention. Importantly, it enables an organization to put all assets online (e.g., from street parking spaces to ships) to enable real-time management of resources for maximum utilization. Innovative DDSs will enable the shipping industry to meet the EU's goals, and in this article, we chart the course of innovation (Figure 2).

The first shipping use of a DDS was in the form of an Automatic identification system (AIS), which provides data about a vessel's state automatically every 3-10 seconds, depending on its speed. In 2000, IMO mandated that by 2005 all cargo ships above a certain gross tonnage and all passenger ships had to deploy an AIS transceiver and regularly transmit specified unencrypted status data. The AIS data stream for individual ships can be detected and made publicly available (e.g., www.marinetraffic.com).

Before AIS could be implemented, the IMO had to define message and communication standards. There are 27 different types of top level messages that can be sent by a ship's onboard AIS transceiver [12]. This is, however, just the beginning of digitization because every asset needs to create a DDS if it is to be managed digitally.

While AIS and green routing are the only implemented innovations of those shown in Figure 2, a path over the next decade or so can be easily envisioned based on research emanating from the STM Validation project ${ }^{5}$ and its predecessor, the MonaLisa project.

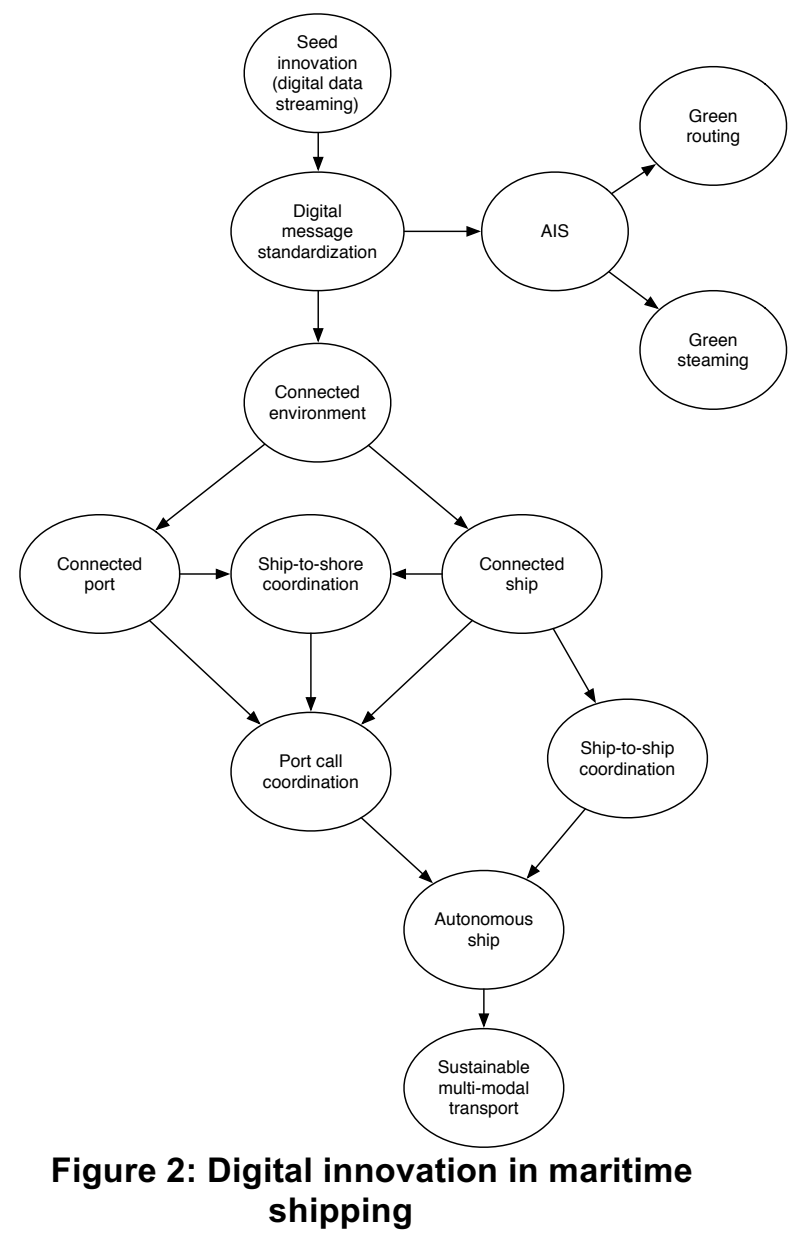

The availability of AIS data provided the raw data to investigate the potential value of implementing two innovations: green routing (the shortest safe distance) and green steaming (the lowest operational speed to arrive on schedule). AIS has become a platform for designing new digital services and spawned firms whose services are based on digital data streams and a firm's digital capabilities [13] to create information.

Green routing means a ship can take the shortest route, constrained by safety and regulations. Such routes are computed by using AIS data on current sea traffic, environmental conditions (e.g., wind and tide), and characteristics of the ship. Safety requires that ships continually operate within a moving zone, or safe haven [14], and that there is sufficient distance from other ships and the shore both fore and aft, starboard and port, and adequate keel clearance. Based on AIS data analysis, green routing offers potential energy savings of $12 \%$ for commercial shipping operating in

\footnotetext{
${ }^{5} \mathrm{http}: / /$ stmvalidation.eu
} 
the Kattegat, a portion of the Baltic Sea between Sweden and Denmark. ${ }^{6}$

Green steaming aims to reduce the amount of energy a ship consumes by promoting just-in-time arrival. The amount of energy used by a ship is determined by its size and speed. Above 14 knots, fuel consumption is an exponential function of speed. Thus, arriving too soon at a port is a waste of fuel and increases costs. Using AIS data on ships arriving at the Port of Gothenburg in Sweden, green steaming can produce emissions and fuel savings of about $4 \%$. The savings are dependent on the level of port congestion. As it rises and a greater percentage of ships need to anchor, the savings will rise, and vice versa [15].

Green routing and steaming are innovations whose economic impact could be validated by analyzing AIS data, but their implementation requires further innovation to create a connected environment. The availability of AIS data provided the wherewithal to digitally 'trial' green innovations.

AIS initiated standardized digital messaging in the shipping industry, and it spawned the realization that DDSs could facilitate a connected environment within the industry. Activities within a port could be coordinated using DDSs and ships could be real-time digitally connected to the shore. Furthermore, the connected environment embraces the notion that sensor networks are deployed to generate DDSs describing the current state of the environment, such as wind speed, current, and tidal movement. Such data can improve vessel performance and increase safety.

In late 2015, two leading communication companies signed an agreement to create the connected ship. Inmarsat and Ericsson plan to provide a managed cloud solution for ship-to-shore communication that will facilitate the sharing of cargo, logistics, and vessel operational data to improve the efficiency of the maritime supply chain. ${ }^{7}$

The purpose of another innovation, the connected port, is to use DDSs to coordinate a ship's port visit to reap the efficiency of just-in-time operations. In many ports, the data necessary for coordination are available, but they are not shared as a DSS among the different actors, so coordination is poor. This means there is a lack of a common situational awareness that is necessary for multiple parties to tightly couple their activities efficiently. PortCDM is one proposal for implementing port call coordination, an innovation stemming from the connected port concept. PortCDM derives state data from existing systems, refines it, and provides the basis for increased coordination

\footnotetext{
${ }^{6}$ http://www.sspa.se/ship-design-and-hydrodynamics/voyageoptimisation-shallow-waters-baltic-sea

${ }^{7}$ http://www.inmarsat.com/news/transforming-the-future-ofthe-connected-ship/
}

capability. PortCDM promises to increase event predictability, facilitate just-in-time operations, reduce waiting times, and raise resource utilization [16].

AIS streams current data about a ship's status. It does not indicate its future path. However, nearly all commercial shipping uses digital navigation systems to chart their course. As a result, a future path is shareable as a DDS once a standardized message is established. This will enable ship-to-ship coordination, which is a critical safety concern when ships are passing or operating in congested waters. Software can be implemented to ensure collisions are avoided and green routes are followed.

The spread of PortCDM and ship-to-ship coordination requires standardization of the message format. A standard is under development for port communications [17], and RTZ is a published XMLbased standard for route exchange among ships. ${ }^{8}$

Autonomous shipping is the penultimate innovation that we can foresee at this point. Firms, such as Rolls Royce, are working on hardware and software systems to create an unmanned ship. An autonomous ship will require no crew, thus saving about USD 3,000-\$4,000 per day and use about 15\% less fuel, because of the removal of human-related facilities. Just like other autonomous vehicles, the unmanned ship will be reliant on DDSs to determine its speed and route. The auto industry's high interest in autonomous cars will provide technology to support autonomous shipping and draw attention to the possibilities of autonomous shipping.

The ultimate goal, as we alluded to in the introduction, is to create a sustainable transport system that enables the world to reap the benefits of trade while minimizing carbon emissions. All aspects of transport must be sustainable. Containerization created the model for driving down the costs of multi-modal transport and STM can drive down carbon emissions to create sustainable multi-model transport. Innovations such as green steaming and port collaboration will reduce the energy and resource requirements of global shipping.

\section{Comparison of the two innovations}

We now jointly consider these prior and promised transformations of shipping. Both the physical and digital innovations start with a seed idea that is not new. The idea of loading goods into a container is centuries old and air transport has tracked planes via a transponder since the Second World War [18]. Additionally, real-time computing has been discussed

http://www.cirm.org/rtz/RTZ\%20Schema\%20version\%201_0.txt 
for at least 50 years [e.g., 19], and DDSs are a current extension of the idea that data can be processed as they are generated.

The seed does not get planted until a person or organization matches the innovation to a problem. In the case of the container, McLean was seeking a way to increase his competitiveness in the shipping industry by major cost reductions. He was willing to upend the system to achieve his goals. In contrast, AIS was introduced by the IMO to promote safety at sea. ${ }^{9}$ The UN assigns the IMO responsibility for the safety and security of shipping and prevention of marine pollution by ships.

Once an innovation has reached a threshold level of system perturbation, other innovations emerge to build on the original implementation and reinvent the entire system until we see emergent outcomes, such as automated container handling, or possibilities, such as autonomous shipping, that were not within the scope and vision of the original innovation. Similar effects have been seen in construction projects where a seed innovation, 3-D digital presentation in building design, created a 'wake' of innovations throughout multiple connected industries [20], though containerization shows that such wakes are not restricted to digital innovations.

The maritime industry is a self-organized ecosystem. The various actors operate independently and competitively, except for episodic tight coupling [21] when several actors need to jointly coordinate their actions, such as a ship berthing at a terminal to load and unload containers. Prior to containerization, the inefficiency of episodic tight coupling was a major cost, mainly because cargo was physically handled multiple times. Containerization, once standards were in place and widely adopted, reduced episodic tight coupling costs related to cargo handling. However, almost all other types of episodic tight coupling were untouched, such as a pilot meeting a ship to guide it into a harbor with the aid of some tugs. Digital innovation, such as port collaboration, is about using DDSs to coordinate episodic tight coupling for greater efficiency. Green steaming, for example, is about sharing data to plan the arrival of a ship when needed port resources are available, which means a ship does not waste energy arriving too soon. It also means a container terminal's utilization is higher because of greater predictability of port activities.

Prior to containerization, one study concluded that for some commodities, freight could be $25 \%$ of the total cost of a product [22]. Now, transport is in the region of $1 \%$ of total product cost, due to productivity increases as large as forty fold [7]. As a consequence,

\footnotetext{
${ }^{9}$ http://www.un.org/en/sc/ctc/docs/bestpractices/32.pdf
}

containerization creatively destroyed the shipping industry, and it was transformed to being dominated by a small number of large ports. The previously large ports that did not adapt became small, and new major players emerged (e.g., New Jersey displaced New York as the major U.S. north-east shipping port). The system built around containerization was driven by innovation to reduce costs because shipping companies compete on price. As with other system-wide innovations, established organizations (e.g., unions) and relationships (e.g., a city and its port) were destroyed and replaced by new structures (e.g., the container terminal) and practices (containerization) [23].

Can we expect digitization to have a similar destructive effect? When freight costs have been driven down to the point of economic irrelevance [7], then digitization has little left to cut. We are not implying that shipping will become less competitive, but rather digitization has minimal scope to cause dramatic freight cost changes. Rather, digital innovation is likely to drive down variability as DDSs are used to enhance coordination to deliver predictable performance. As a result, digitization will lead to higher levels of resource utilization and less requirement for capital investment.

As well as efficiency, digitization is also motivated by safety and environmental goals, issues that were not driving forces during the containerization revolution. Indeed, AIS was introduced to enhance safety, and we expect that the increased situational awareness resulting from data sharing will help reduce accidents. Green routing and steaming and increased resource utilization will reduce the environmental impact of the maritime industry, as they will decrease the need for ships and supporting facilities, such as terminals and cranes.

Innovation around containerization reduced radically the cost of shipping, both ocean and land. Innovation around DDSs will eke out some more cost savings by raising the level of coordination among the many autonomous actors and provide data for motivating and coercing environmentally sound behavior. These differences are reflective of the proposition that the economy is going through a shift in dominant logic towards sustainability [24]. Containerization commenced when production dominant logic was forefront, and it resulted in a massive increase in productivity, which also contributes to sustainability, though it was not then a societal goal. Digitization of shipping is occurring when sustainability has become an urgent global issue and is now driving many governmental and organizational decisions. The connected container that streams digital data about its status and contents will merge these major physical and digital innovations in shipping. 
Both seed innovations are examples of modularity, a general systems concept, that has influenced IS [25, $26]$ and management thinking [27, 28]. A container reduces the complexity of handling freight by breaking it down into modules, fixed size physical containers that interlock to create stackable storage. A DDS is a set of modularized and standardized digital data packages whose access can be dynamically controlled via an API. Modularity galvanized transport innovation because a container was standardized so it was not limited for sea transport. Containers have since been reused for housing and portable production systems. Similarly, a DDS is a reusable concept that is not industry specific because of its digital nature.

\section{How is digital innovation similar?}

The highly autonomous nature of global shipping makes widespread industry adoption of an innovation challenging without the intervention of an international body, such as the IMO, to set standards and direction, as it did with AIS. An innovation, such as a container or DDS, is an opportunity, but its realization is dependent on governance structures that create workable standards, and set the stage for positive externalities. Standard setting for a self-organizing ecosystem is a slow process of negotiation to ensure that powerful vested interests will vote for a potential standard. The IMO Council, for example, has representatives from 40 nations.

Innovation spawns innovation in two directions. First, complementary physical or digital innovations need to be developed and implemented to build a new system for handling the problem the seed innovation promises to address. Second, organizational innovations emerge as entrepreneurial actors see the prospects for the innovation to displace established players by creating new structures and procedures. For example, in the shipping industry, many of the dominant ports of the old era were quickly pushed aside by upstarts (e.g., Felixstowe replaced London as the UK's major port), which could quickly assemble the financial and physical resources to create a container port. It is too soon to see the impact of digital innovation on the structure of the industry, but it is most likely to impact the current data handlers and information hubs, shipping agents, who are the current coordinators of port activity. The winners are likely to be those who can assemble DDSs, from sources both within and without the shipping industry, to create value for other actors in the transport sector.

\section{How is digital innovation different?}

Digital standardization is easier to implement because digital data can be readily translated between propriety formats and industry standards. Vested interests have more at stake when their assets are physical. It is costly to convert a dockyard of $35 \mathrm{ft}$ $(10.7 \mathrm{~m})$ containers to the ISO standard of $20 \mathrm{ft}(6.1 \mathrm{~m})$, whereas changing a message format might be as simple as writing an XML stylesheet. Also, software can be readily copied at low cost. While implementation can be expensive, the capital requirements are typically orders of magnitude lower than building a ship or container terminal. Consequently, digital standardization should rapidly create positive externalities and accelerate adoption. This is evident in the dominance of digital platforms, such as Facebook and Amazon.

DDSs are multiply recombinant, or generative [13], and can create new information services. We expect that entrepreneurs will emerge, as we already see with AIS data, to merge multiple DDSs from diverse sources to create information services, such as green routing, for those involved in the transport of goods between producer and consumer. DDSs are strands for information service innovation. Digital innovation ignites further innovation because input resources, such as AIS data, are often free and require minimal investment in equipment, open source software is free, and cloud computing is inexpensive.

Traditional physical innovation has often been locked within an industry until some perspicacious individual sees an industry-hopping opportunity. For example, Guttenberg's creation of a printing press might have been inspired by the wine press [29]. Digital innovations are inherently fungible. While IBM's hierarchical database was designed to support NASA's Apollo project, ${ }^{10}$ it was clearly not limited to one industry but applicable to all.

Digital innovations inherently create digital data, and thus captured latency is close to zero (Figure 3). Consequently, decision-making can be considerably accelerated. Reducing decision-making time with improved quality is a key goal of the STM project. Digitization lays the foundation for improved decisionmaking because it creates the fundamental feedstock of the data to information to decision-making supply chain. Of course, organizations need to implement this process.

http://www.ibm.com/support/knowledgecenter/SSEPH2_11.1.0/com. ibm.imsintro.doc.intro/intro_imsandapollo.html 


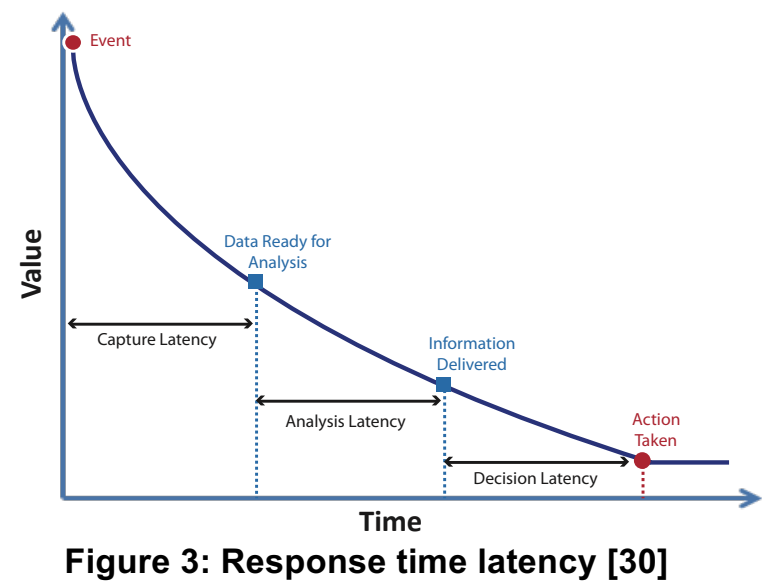

Digital innovations can directly lead to improved decision-making, the central activity of an organization [31]. Whereas, physical innovations are primarily about increasing the efficiency of operational actions, though if data are collected as part of the innovation's implementation, there will be likely improvements in decision-making. The IoT involves, among other things, the embedding of digital capabilities within physical assets, such as adding digital intelligence to a container to improve decision-making related to that object and the setting in which it is used. Thus we see the merging of physical and digital objects to generate DDSs about the state of an organization's assets. Consequently, we can expect the IoT to increase both operational efficiency and decision effectiveness.

Both innovations invoke modularization, but in different ways. The critical issue of containerization is agreement on a set of standard module sizes and their construction to support loading and stacking. On the digital side, it is about the message module in terms of structure and content and frequency of transmission. These design questions reflect inherent differences between physical and digital innovations [13] .

\section{Contribution}

Our contribution is to compare a series of analog and digital innovations in a large global industry. We illustrate how the seed innovation galvanizes a series of complementing innovations designed to solve the problem addressed by the seed. Thus, innovation is seen as a series of coordinated and connected actions to take the seed innovation and fully exploit it to move the industry to an order of magnitude higher level of performance. We also assess the differences and similarities of the two innovations, but our focus is on digital innovation.
One definition of digital innovation asserts that it is "the carrying out of new combinations of digital and physical components to produce novel products" and it relies on digitization [32]. Novel products, however, are not what we see in the STM project. Rather, we see novel emerging processes such as green steaming and port collaboration. Innovation is driven by problems, and solutions can be a combination of both product and process. Product innovation can precede process (the AIS transponder is necessary to generate a DDS to permit the new process of green steaming) and process innovation can precede product (port collaboration is a process and new products are implemented, such as a tablet app for linesmen to report the status of a berth) to generate a DDS). Such patterns of innovation are also evident in the wake of the introduction of digital 3-D architectural representation [20].

Another and broader definition asserts that digital innovation is "a product, process, or business model that is perceived as new, requires some significant changes on the part of adopters, and is embodied in or enabled by IT" [33]. We consider this is still rather limited, as product and process are a limited view of innovation, when at least 12 forms have been identified [34]. Thus, we define digital innovation as the creation of a novel outcome that relies upon digitization for its transformative effects. We have broadened the definition by allowing for various combinations of what, how, whom, and where that drive innovation [34], and qualified it by specifying a metamorphic result from digitization. We thus set a high standard for digital innovation.

Note that we require digital innovation to rely upon digitization, which prompts the question whether digital innovation is just innovation with a faddish adjective? The distinguishing feature, we assert, is the reliance on digitization to produce novel outcomes. Green routing, for example, is based upon digitizing weather, current, tide, wave, and ship data to generate an optimum route. Sensor networks are required to measure and digitize environmental data to facilitate green routing. Similarly, port collaboration requires that the assets of a port generate digital data streams reporting their status so that there is real-time situational awareness to enable high levels of coordination. Digital innovations, as these examples illustrate, can improve decision-making, and the STM project is fundamentally about making smarter decisions regarding safety and resource utilization in the shipping industry. Whereas, innovations around the container were motivated by driving down costs by creating a system for efficiently handling standardized containers. Because digital innovation produces data streams, its most transformative effects will likely be 
on decisions, because data are the raw material of decisions.

By looking at the sequencing of two innovations within an industry, we have highlighted the notion of a seed innovation, which germinates a path that determines a sequence of innovations complementing the original goal but possibly not envisioned when it was set. Fundamental characteristics of the seed in each case determine the path. The physical nature of a container highlights the problems of safe and efficient handling, movement, and stowage. In contrast, the realtime nature of a DDS lends itself to innovation around information creation and enhanced decision-making. This leads us to a research question:

RQ1: What characteristics of the seed digital innovation determine the successful solution of the initiating problem?

Furthermore, how does a seed get converted to a standard, particularly in a self-organizing ecosystem? AIS was essentially adopted by IMO fiat because safety is so critical to the seafaring ethos, but what about the instantiation of a DDS standard for enabling green steaming? Will sustainability be a compelling force for standard creation and adoption?

RQ2: What process for transformation of the seed digital innovation into an industry standard determines the successful solution of the initiating problem?

Innovation is frequently sequential. One innovation begets another. The sail enabled early traders to extend their reach, but then they needed to discover how to sail into the wind, navigate when they could no longer see the coast, and so on.

RQ3: What determines the sequencing of digital innovations? Is there a logic to the incrementalism?

An innovation has often been locked within an industry until some clear-sighted individual sees a parallel. Air Traffic Management was an initial model for STM, but the driving digital innovation is now DSS, which is a generic digital capability. Thus, we can also think of digital innovations as networked, in the sense that they cross boundaries and get spliced into a new industry. Digital splicing might be easier than physical splicing because of the malleability of digital standards.

\section{References}

1. Maritime Knowledge Centre, International shipping facts and figures - information
RQ4: What determines the networking of digital innovations so they cross industry boundaries? Are some boundaries more permeable than others?

A study of two innovations, one past and one preceding, in one industry is insufficient grounds for theorizing. A thorough analysis of the differences between analog and digital innovations requires examining multiple and diverse industries and an study of the diffusion of innovation beyond an industry. At this stage of inquiry, the contribution must be limited to establishing a set of key questions to guide further research.

\section{Conclusion}

Innovations rarely pop into existence. They exist within a stream and respond to other innovations, but occasionally one variation of an innovation, its timing, or the grit of a determined individual, makes it transformative because it becomes a standard and thus gains the persuasive power of positive externalities. The persistence of McLean made containers a success, along with the creation of a standard. AIS, a variation on a DSS, has shown the shipping industry the potential of digital innovation based on data sharing to improve decision-making

Industry transformation is a connected stream of complementary innovations. In a digital world, the generic nature of digital innovations should accelerate connectivity because of the programmability of digital objects, but we need to understand more about digital innovation seeds, digital standard setting, digital innovation sequencing, and networking. This means scholars need to get immersed in the study of digital innovation streams [e.g., 20] rather than isolated digital innovations. The unit of analysis becomes an industry and the ecosystem in which it operates and the time period is years because that is the nature of transformation.

A sustainable shipping system is one step in designing an ecologically sustainable world, a goal whose attainment will require a torrent of integrated digital innovations, such as the smart grid and smart cities. Digital innovation lays the tracks for a smarter world by generating the DDSs necessary for smart decisions.

resources on trade, safety, security, environment. 2012, IMO.

2. UNCTAD, Review of maritime transport. 2013.

3. Psaraftis, H.N. and C.A. Kontovas, CO2 emission statistics for the world commercial 
fleet. WMU Journal of Maritime Affairs, 2009. 8(1): p. 1-25.

4. Cames, M., et al., Emission reduction targets for international aviation and shipping. 2015, European Parliament.

5. Cuff, M., Maritime industry refuses to change emissions course, in GreenBiz. 2016.

6. Elkington, J., Cannibals with forks. The triple bottom line of 21 st century. 1997, Oxford: Capstone.

7. Levinson, M., The box: how the shipping container made the world smaller and the world economy bigger. 2010: Princeton University Press.

8. Glaeser, E.L. and J.E. Kohlhase, Cities, regions and the decline of transport costs*. Papers in regional Science, 2004. 83(1): p. 197-228.

9. Ripley, D., The Little Eaton Gangway and Derby Canal. 1993: Oakwood Press.

10. Ricardo, D., On the Principles of Political Economy and Taxation: London. 1817: G. Bell $\&$ Sons.

11. Pigni, F., G. Piccoli, and R.T. Watson, Digital Data Streams: Creating value from the real-time flow of big data. California Management Review, 2016. 58(3): p. 5-25.

12. International Telecommunications Union (ITU), Recommendation 1371-4,“Technical characteristics for an automatic identification system using time-division multiple access in the VHF maritime mobile band,". 2010.

13. Yoo, Y., et al., Organizing for innovation in the digitized world. Organization Science, 2012. 23(5): p. 1398-1408.

14. Porathe, T., et al. Ship traffic management route exchange: acceptance in Korea and Sweden, a cross cultural study. in Proceedings of the International Symposium Information on Ships, ISIS 2014. 2014.

15. Watson, R.T., H. Holm, and M. Lind, Green steaming: A methodology for estimating carbon emissions avoided, in International Conference on Information Systems. 2015: Forth Worth, TX.

16. Lind, M., et al., Overcoming the inability to predict - a PortCDM future, in 10th International Harbor Masters' Association Congress - Global Port \& Marine Operations. 2016: Vancouver, Canada.

17. Lind, M. and S. Haraldson, Port call message standard - constituents, use cases, information model, and message format, in STM validation project. 2016.

18. Bowden, L., The story of IFF (identification friend or foe). Physical Science, Measurement and Instrumentation, Management and
Education-Reviews, IEE Proceedings A, 1985. 132(6): p. 435-437.

19. Martin, J., Design of real-time computer systems. 1967: Prentice-Hall.

20. Boland Jr, R.J., K. Lyytinen, and Y. Yoo, Wakes of innovation in project networks: The case of digital 3-D representations in architecture, engineering, and construction. Organization science, 2007. 18(4): p. 631-647.

21. Watson, R.T. and M.-C. Boudreau, Energy Informatics. 2011, Athens, GA: Green ePress.

22. MacMillan, D.C. and T.B. Westfall, Competitive general cargo ships. 1960. 68: p. 843.

23. Yoo, Y., R.J. Boland Jr, and K. Lyytinen, From organization design to organization designing. Organization Science, 2006. 17(2): p. 215-229.

24. Watson, R.T., M. Lind, and S. Haraldson. The emergence of sustainability as the new dominant logic: Implications for Information Systems. in International Conference on Information Systems. 2012. Orlando, FL.

25. Yourdon, E. and L.L. Constantine, Structured design: Fundamentals of a discipline of computer program and systems design. 1979: PrenticeHall, Inc.

26. Yoo, Y., O. Henfridsson, and K. Lyytinen, Research commentary-The new organizing logic of digital innovation: An agenda for information systems research. Information systems research, 2010. 21(4): p. 724-735.

27. Baldwin, C.Y. and K.B. Clark, Managing in an age of modularity. Managing in the modular age: Architectures, networks, and organizations, 2003. 149.

28. Yoo, Y., The tables have turned: how can the information systems field contribute to technology and innovation management research? Journal of the Association for Information Systems, 2013. 14(5): p. 227.

29. Wolf, H.J., Geschichte der druckpressen. 1974: Interprint.

30. Hackathorn, R., Current practices in active data warehousing. Bolder Technology, 2002.

31. Huber, G.P., The nature and design of postindustrial organizations. Management Science, 1984. 30(8): p. 928-951.

32. Yoo, Y., O. Henfridsson, and K. Lyytinen, Research Commentary--The New Organizing Logic of Digital Innovation: An Agenda for Information Systems Research. Information Systems Research, 2010. 21(4): p. 724-735.

33. Fichman, R.G., B.L. Dos Santos, and Z. Zheng, Digital Innovation as a Fundamental and Powerful Concept in the Information Systems 
Curriculum. Mis Quarterly, 2014. 38(2): p. 329343.

34. Sawhney, M., R. Wolcott, and I. Arroniz, The 12 different ways for companies to innovate. MIT Sloan Management Review, 2006. 47(3): p. 7581. 